\title{
Der blaue Klassiker seit 50 Jahren
}

\author{
Sterillium ${ }^{\circledR}$ - Revolution des Berufsalltags in Gesundheitseinrichtungen
}

Sterillium ${ }^{\circ}$ ist der Klassiker der alkoholischen Desinfektion im Bereich der hygienischen und chirurgischen Händedesinfektion. Vor 50 Jahren wurde das erste marktfähige Hände-Desinfektionsmittel auf Alkohol-Basis in der Hamburger Bacillolfabrik Dr. Bode \& Co. entwickelt.

Sterillium revolutionierte den Berufsalltag in Gesundheitseinrichtungen, denn die Händedesinfektion wurde sicherer, effizienter und mit diesem Produkt endlich auch noch hautfreundlich. Seither erfolg-

\section{Wir forschen für den Infektionsschutz. www.bode-science-center.de}

reich in der Praxis bewährt und umfassend wissenschaftlich geprüft, steht Sterillium ${ }^{\circ}$ für zuverlässige Wirksamkeit, gute Hautverträglichkeit und maximale Sicherheit.

$\mathrm{Zu}$ diesem Klassiker hat sich in den vergangenen Jahrzehnten ein Sortiment von Qualitätsprodukten entwickelt, mit dem HARTMANN von Routine- über Risiko- bis zu Ausbruchssituationen allen Herausforderungen im Gesundheitswesen gerecht wird.

Die Forschungsarbeit rund um Sterillium $^{\circ}$ geht auch heute unvermindert weiter. Mit etwa 60 wissenschaftlichen Veröffentlichungen in Fachzeitschriften ist
Sterillium ${ }^{\circ}$ das am häufigsten untersuchte Hände-Desinfektionsmittel weltweit. Seit 2011 treibt das BODE SCIENCE CENTER, wissenschaftliches Kompetenzcenter von HARTMANN, engagiert und konsequent die Forschungsarbeit zu Sterillum ${ }^{\circ}$ und zur Händedesinfektion voran. Prof. Günter Kampf, wissenschaftlicher Leiter des BODE SCIENCE CENTER, bringt die Sterillium ${ }^{\circ}$-Geschichte prägnant auf den Punkt: „Sterillium ${ }^{\circledR}$ war immer mehr als ein Produkt zur Händedesinfektion. Sterillium war und ist ein Gesamtkonzept zur Verbesserung der Hygiene“.

Die gebrauchsfertigen alkoholischen Sterillium -Produkte zur Händedesinfektion zeichnen sich aus durch:

- umfassende Wirksamkeit bei der hygienischen Händedesinfektion in 30 Sek.

- sichere Wirksamkeit bei der chirurgischen Händedesinfektion in 1,5 Min.

- exzellente Hautverträglichkeit

\section{Sterillium ${ }^{\circledR}$-Produkte} auf einen Blick

\section{Sterillium ${ }^{\circ}$}

Der Klassiker - seit 50 Jahren erfolgreich. Dank seiner verlässlichen antimikrobiellen Wirksamkeit und seiner hervorragenden Hautfreundlichkeit der Favorit von Millionen von Nutzern rund um die Welt.

\section{Sterillium ${ }^{\circ}$ classic pure}

Die farbstoff- und parfümfreie Variante des Klassikers Sterillium ${ }^{\circ}$ Besonders für die sensible Haut geeignet und Nummer 1 in Deutschlands Kliniken.
Sterillium $^{\circ}$ Tissue Das praktische Hände-Desinfektionstuch für unterwegs.

\section{Sterillium ${ }^{\circ}$ med}

Das Hände-Desin-

fektionsmittel mit umfassender Wirksam-

keit gegen Viren (inkl. Noroviren ${ }^{*}$ ) innerhalb der hygienischen Händedesinfektion. Mit bewährtem Hautpflegekomplex. Farbstoff- und parfümfrei.

\section{Sterillium ${ }^{\circ}$ Gel}

Hoch wirksames Hände-Desinfektionsgel mit einem breiten Wirksamkeitsspektrum und bewährtem Feuchtigkeitskomplex.

\section{Sterillium ${ }^{\ominus}$ Virugard}

Hoch wirksames viruzides Hände-Desinfektionsmittel für alle Risikobereiche. Erstes RKI A/B-gelistetes Produkt. Die hautverträgliche Alternative zu Produkten auf Chlor- und Phosphorsäurebasis.

\section{Informationen:}

PAUL HARTMANN Ges.m.b.H.

IZ-NÖ-Süd, Straße 3, Objekt 64

A-2355 Wiener Neudorf

Tel.: +43 2236646 30-0

E-Mail: office@at.hartmann.info

www.at.hartmann.info

2014 (GPI Krankenhaus-Sachbedarfs-Studie, DKB: alkohol. Händedesinfektion, Krankenhausbereich Deutschland)

Getestet am murinen Norovirus (MNV)

Weitere Informationen zu Sterillium sowie praktische Tipps rund um die Händedesinfektion sind auf der neuen Sterillium-Website unter www.sterillium.at verfügbar. der im Bereich von Medizin- und Hygieneprodukten weltweit tätigen Hartmann Gruppe (Firmenzentrale Heidenheim/Brenz, Deutschland). HARTMANN bietet Systemlösungen in den Hauptgeschäftsfeldern Wundbehandlung, Inkontinenzhygiene, OP-Risiko-

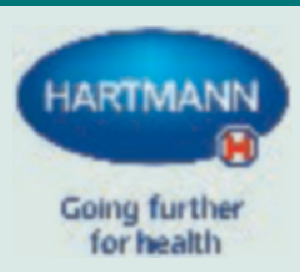
schutz und Desinfektion.

Mit seinem fokussierten medizinischen Portfolio und seinen an Marktbedürfnisse angepassten Serviceleistungen ist Hartmann heute ein anspruchsvoller und leistungsfähiger Partner seiner Kunden.

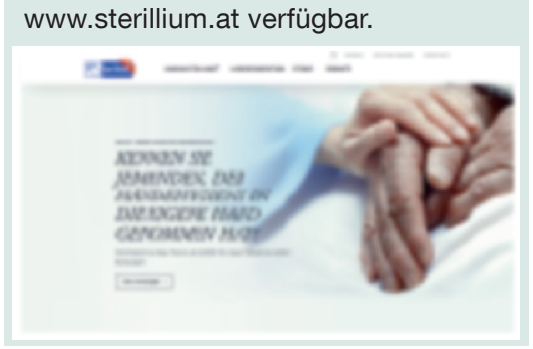

